\title{
Phytochemical constituents, antioxidant activity and antimicrobial potential of Pulicaria incisa (lam.) DC as a folk medicinal plant
}

\author{
Omar A. EL-Shahaby ${ }^{1}$, Mustafa M. El-Zayat ${ }^{2}$, Reham Rabei $^{1}$, Heshmat Soliman Aldesuquy ${ }^{1}$
}

${ }^{1}$ Botany Department, Faculty of Science, Mansoura University, ET-35516, Mansoura, Egypt

${ }^{2}$ Unit of Genetic Engineering and Biotechnology, Faculty of Science, Mansoura University, ET-35516, Mansoura, Egypt

\section{A R T I C L E I N F O}

\section{Article history:}

Submitted: 2019-11-02

Revised: 2019-11-08

Accepted: 2019-11-09

Available online:2019-11-24

Manuscript ID: PCBR-1911-1067

\section{G R A P H I C A L A B S T RAC T}

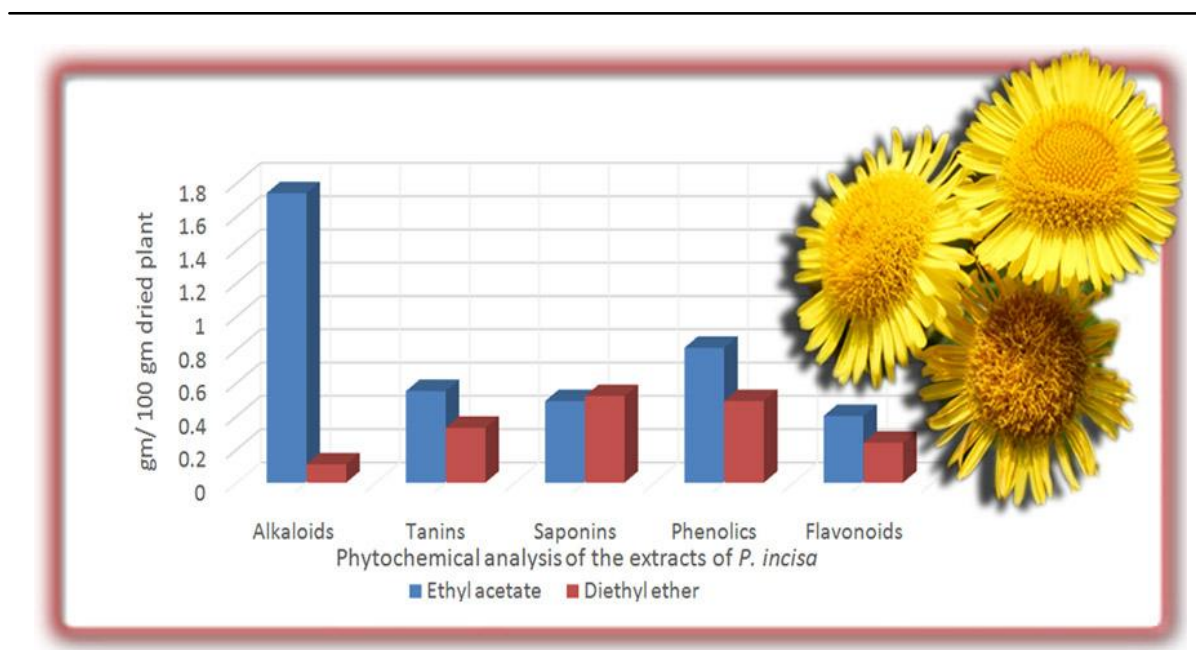

\begin{tabular}{l} 
K E Y W O R D S \\
\hline Pulicaria incisa \\
Phytochemical \\
Constituents \\
Antioxidant (DPPH assay) \\
Antimicrobial activity \\
\hline
\end{tabular}

\begin{abstract}
A B S T R A C T
The species belonging to the genus Pulicaria are well known for their traditional uses in folklore medicine, active chemical constituents and pharmacological activities. Therefore, this study aimed to determine the active constituents, antioxidant activity and antimicrobial potential of Pulicaria incisa (lam.) DC extracts. Ethyl acetate and diethyl ether extracts of the dried aerial parts of $P$. incisa were prepared. The active secondary constituents (alkaloids, phenolics, flavonoids and tannins) were quantitatively determined. The active constituents in the ethyl acetate extract were higher than those of diethyl ether extract. The ethyl acetate extract expressed higher antioxidant activity in terms of diphenyl picryl hydrazyl (DPPH ${ }^{\bullet}$ ) radical scavenging assay in comparison with ascorbic acid as a reference standard. The antimicrobial activity analysis revealed that the ethyl acetate extract expressed antimicrobial activity against Staphylococcus aureus, Staphylococcus epidermidis, Erwinia carotovora and Candida albicans while that of diethyl ether expressed activity against Bacillus subtillis, Erwinia carotovora and Candida albicans. In conclusion the antioxidant and anti-microbial activity of the studied extracts of $P$. incisa may be attributed to its richness with the medicinally active metabolites.
\end{abstract}




\section{Introduction}

Genus Pulicaria of the family Asteraceae has around one hundred species distributed in Europe, North Africa and Asia [1]]. Pulicaria incisa (lam.) DC is a medicinal plant known as wild tea or Shay Gebeli and is used by natives of upper Egypt and by Bedouins as a decoction, tea substitute and for treatment of heart diseases [2]. It is characterized by its aromatic smell and essential oil content. $P$. incisa was reported to be used in Sudanese traditional medicine as a tonic, antispasmodic, hypoglycemic in addition to its usage as an ingredient of a local perfume. The traditional medicinal properties of this plant have been approved through scientific research as several studies were done on it revealed its hypo-cholestremic, antimicrobial, anticancer and antioxidant properties [2-10].

It is common in Egypt throughout the Sahara, including the Red Sea region and Sinai. It is grown in non-saline wadi beds and has a wide ecological range from sandy to gravelly soils but sand-loamy soils are preferable [11].

The evolution of antibiotic-resistant microbes like Staphylococcus aureus decrease the number of antibiotics used for the treatment of clinical infections and this has motivated the search for novel antimicrobial drugs from natural sources [12].

This study aims to evaluate the phytochemical constituents, antioxidant and antimicrobial potential of two different extracts prepared from P. incisa.

\section{Materials and methods}

\section{Plant material}

The aerial parts of $P$. incisa were collected from their natural habitat in Saint Catherine protectorate during the period from August to mid-September 2018. The samples botanical identities were identified and authenticated according to Bolous [13]. Two kilos of aerial parts of $P$. incisa were air dried in shade for 20 days and grinded to be ready for use.

\section{Preparation of the plant extracts}

Extraction of the target species was carried out using two different extraction solvents including ethyl acetate and diethyl ether. 10 grams of the dried plant was extracted by shaking for three hours at $250 \mathrm{rpm}$ with $200 \mathrm{ml}$ of ethyl acetate and the same was done for diethyl ether. Subsequently, the extracts were filtered then evaporated to dryness using rotary evaporator.

\section{Determination of the active secondary metabolites Total phenolics}

Phenolics content was measured using Folin Ciocalteu assay described by Lin and Tang [14] and determined as gram gallic acid equivalent (GAE)/ 100-gram air dried.

\section{Total flavonoids}

Flavonoids content was measured using aluminum chloride assay described by Chang et al. [15] and determined as gram quercetin equivalent $(\mathrm{QE}) / 100-$ gram air-dried plant.

\section{Total alkaloids}

Alkaloids content was measured using 1,10phenanthroline method described by Singh et al. [16] and determined as gram alkaloids / 100-gram air-dried plant.

\section{Total tannins}

Tannin content was determined by Vanillin hydrochloride method of Sadasivam, \& Maickam [17] and determined as gram gallic acid equivalent/ 100gram air-dried plant). 


\section{Evaluation of antioxidant activity DPPH• Assay}

The efficacy of the studied extracts against DPPH• free radical was determined according to the assay described by Kitts et al [18]. The antioxidant activity was calculated as the amount of antioxidant needed to diminish the initial $\mathrm{DPPH} \cdot$ concentration by $50 \%$ ( $\mathrm{IC}_{50}$ ). Ascorbic acid was used as a standard reference compound.

\section{Screening of the antimicrobial activity \\ Disc diffusion assay}

The antimicrobial potential of $P$. incisa extracts was determined using filter paper disc assay [19].

\section{Tested organisms}

Bacillus subtilis DMS-1088, Klebsiella pneunomonia ATCC-10031, Staphylococcus aureus ATCC-6538, Staphylococcus epidermidis EMCC number-1353t, Escherichia coli ATCC-10536, Erwinia carotovora ATCC$15713^{\text {tm }}$ and one pathogenic fungal strain, Candida albicans EMCC number-105.

\section{Results and Discussions}

Previous phytochemical studies on Pulicaria species reported the ability of them to synthesize phenolics, flavonoids, tannins and terpenoids. Such compounds from Pulicaria found to have potential bioactivities and to be a promising source for new drugs and higher value products [20]. These could be helpful for the protection of humans against chronic diseases. For instance, phenolics have many biological features such as antibacterial, antiinflammation, antiaging, anticarcinogen and cardiovascular protection. Flavonoids are potent water-soluble free radical scavengers useful in preventing oxidative cell damage and possess anticancer activity in addition to their antimicrobial activity. Alkaloids protect against several chronic diseases [21-24].
The phytochemical screening of ethyl acetate and diethyl ether extracts of $P$. incisa revealed the presence of medicinally active metabolites like alkaloids, tannins, phenolics, flavonoids, glycosides and terpenoids. These active compounds were quantitatively analyzed and the results obtained revealed that ethyl acetate extract was higher in its active constituents than diethyl ether extract and the ethyl acetate extract was rich in its active metabolites in considerable amounts than those of diethyl ether extract (Table 1).

Table 1- The estimated secondary metabolites in $P$. incisa

\begin{tabular}{ccc}
\hline Extract & $\begin{array}{r}\text { Ethyl } \\
\text { acetate }\end{array}$ & Diethyl ether \\
\hline TA & 1.74 & 0.11 \\
TT & 0.55 & 0.33 \\
TS & 0.49 & 0.52 \\
TP & 0.81 & 0.49 \\
TF & 0.40 & 0.24 \\
\hline
\end{tabular}

$\mathrm{TA}=$ total alkaloids expressed as gram alkaloids / 100gram air-dried plant, $\mathrm{TS}=$ total saponins expressed as gram saponins / 100-gram air-dried plant, TT= total tannins expressed as gram of gallic acid equivalents/100-gram air-dried plant, $\mathrm{TP}=$ Total phenolics expressed as gram of gallic acid equivalents/100-gram air-dried plant, $\mathrm{TF}=$ Total flavonoids expressed as gram catechin equivalent per 100-gram air-dried plant.

The phenolics and flavonoids present in the prepared extracts in variable quantities are well known as potent antioxidant compounds [24-26] and could be contributed to the antioxidant activity of the studied extracts. The antioxidant activity of $P$. incisa extracts are reported in Table 2 .

Table 2- Antioxidant activity of the extracts prepared from P. incisa

\begin{tabular}{lccc}
\hline Extract & $\begin{array}{c}\text { Ethyl } \\
\text { acetate }\end{array}$ & $\begin{array}{c}\text { Diethyl } \\
\text { ether }\end{array}$ & $\begin{array}{c}\text { Ascorbic } \\
\text { acid }\end{array}$ \\
\hline $\mathrm{IC}_{50}$ & 0.009 & 0.14 & 0.023 \\
\hline
\end{tabular}


The antioxidant activity was measured using DPPH• radical assay. The antioxidant scavenging activity for $\mathrm{DPPH}^{\cdot}$ is attributed to its hydrogen-donating ability [27]. Ascorbic acid was used as the standard reference compound (Table 2). The strongest activity was detected in the ethyl acetate that was higher in its antioxidant activity than the reference standard and diethyl ether extract. The antioxidant activity attributed to the presence of the active phytochemical constituents as phenolics, flavonoids, Alkaloids, saponins and tannins as reported in Table 1.

\section{Antimicrobial Assessment}

There were several studies which have been done for screening the antimicrobial potential of pulicaria species where P. jaubertii and P. stephanocarpa showed antimicrobial potential against Bacillis subtilis, $P$. inuloides against Streptococcus pneumoniae while essential oils from $P$. incisa exhibited activity against Streptococcus pneumonia, E. coli , Bacillus subtilis, Aspergillus fumigatus, Syncephalastrum racemosum and Geotricum candidum[28, 29]. It has been reported in the literature that the main constituents express the antimicrobial activity of the plant extracts are phenolics, flavonoids, terpenoids, essential oils, alkaloids, lectins, and polypeptides[풍.

The antimicrobial activity of $P$. incisa ethyl acetate and diethyl ether extracts were tested using Bacillus subtilis DMS-1088, Klebsiella pneunomonia ATCC-10031, Staphylococcus aureus ATCC-6538, Staphylococcus epidermidis EMCC number-1353t ${ }^{\mathrm{t}}$ Escherichia coli ATCC10536, Erwinia carotovora ATCC-15713 ${ }^{\mathrm{tm}}$ and one pathogenic fungal strain, Candida albicans EMCC number-105. The tested ethyl acetate and diethyl ether extracts expressed significant inhibition zones in a dosedependent manner. The antimicrobial activity analysis revealed that the ethyl acetate extract expressed antimicrobial activity against Staphylococcus aureus, Staphylococcus epidermidis, Erwinia carotovora and Candida albicans while that of diethyl ether expressed activity against Bacillus subtillis, Erwinia carotovora and Candida albicans and all the obtained results were compared with the antibiotic Streptomycin as illustrated in Table 3.

Table 3- Antimicrobial activity of $P$. incisa ethyl acetate and diethyl ether extracts

\begin{tabular}{llcc}
\hline Microorganisms & \multicolumn{2}{l}{ Diameter of inhibition zone (mm) } & Streptomycin \\
\hline Erwinia carotovora & Ethyl acetate & Diethyl ether & 17 \\
Klebsiella Pneumoniae & 9.5 & 9 & - \\
Escherichia coli & - & - & 14 \\
Bacillus subtillis & - & 7.5 & 10 \\
Staphylococcus aureus & - & - & 18 \\
Staphylococcus epidermidis & 11 & - & 12 \\
Candida albicans & 8.5 & 10 & \\
\hline
\end{tabular}

Zone of inhibition measured in mm and included filter paper disk diameter (6mm); "-": no inhibition. 


\section{Conclusion}

The obtained results illustrated that $P$. incisa could be regarded as a potential source of useful drugs. The phytochemicals in this plant justifies its traditional medicinal uses. The results of this study in addition to those from previous studies could be considered as a reference to the antioxidant and antimicrobial activity of $P$. incisa with biologically active and stable components. Thus, a scientific foundation to use this plant in medicine can be profound to improve the local user's healthcare.

\section{Competing interests}

We declare that we have no competing interests.

\section{References:}

[1] C.A. Williams, J.B. Harborne, J.R. Greenham, R.J. Grayer, G.C. Kite and J. Eagles, Variations in lipophilic and vacuolar flavonoids among European Pulicaria species. Phytochemistry, 64 (2003) 275283.

[2] M.F. Ramadan, M.M.A. Amer and W. Abd El-Gleel, Impact of Pulicaria incisa, Diplotaxis harra and Avicennia marina as hypocholesterolemic agent. WISSENSCHAFTLICHE VERLAG MBH, 103 (2007) 320-327.

[3] M. Boumaraf, R. Mekkiou, S. Benyahia, J.-c. Chalchat, P. Chalard, F. Benayache and S. Benayache, Essential oil composition of Pulicaria undulata (L.) DC.(Asteraceae) growing in Algeria. Int. J. Pharmacogn. Phytochem. Res, 8 (2016) 746-749.

[4] A. Elmann, A. Telerman, S. Mordechay, H. Erlank and R. Ofir, Antioxidant and astroprotective effects of a Pulicaria incisa infusion. Oxidative medicine and cellular longevity, 2012 (2012)

[5] R. Mansour, A. Ahmed, F. Melek and N. Saleh, The flavonoids of Pulicaria incisa. Fitoterapia, 61 (1990) 186-187.

[6] N. Saleh, Global phytochemistry: the Egyptian experience. Phytochemistry, 63 (2003) 239.

[7] W. Abd El-Gleel and M. Hassanien, Antioxidant properties and lipid profile of Diplotaxis harra, Pulicaria incisa and Avicennia marina. Acta alimentaria, 41 (2012) 143-151.

\section{Authors' contributions}

All authors shared in supplying all laboratory and chemical substances used in this study, designing the experiment, analyzing the data, and also drafting the manuscript. All authors read and approved the final manuscript.

\section{Acknowledgements}

We are thankful to the unit of genetic engineering and biotechnology, Faculty of Science, Mansoura University for the support it provided for us.

[8] S. Mohammadi, A. Taheri and Z. Rezayati-Zad, Ultrasensitive and selective non-enzymatic glucose detection based on pt electrode modified by carbon nanotubes@ graphene oxide/nickel hydroxideNafion hybrid composite in alkaline media. Progress in Chemical and Biochemical Research, 1 (2018) $1-10$.

[9] M. Stavri, K. Mathew, A. Gordon, S.D. Shnyder, R.A. Falconer and S. Gibbons, Guaianolide sesquiterpenes from Pulicariacrispa (Forssk.) Oliv. Phytochemistry, 69 (2008) 1915-1918.

[10] E.A. Shahat, R.O. Bakr, O.A. Eldahshan and N.A. Ayoub, Chemical Composition and Biological Activities of the Essential Oil from Leaves and Flowers of Pulicaria incisa sub. candolleana (Family Asteraceae). Chemistry \& biodiversity, 14 (2017) e1600156.

[11] M. Sheded, Vegetation pattern along an edaphic and climatic gradient in the Southern Eastern Desert of Egypt. Feddes Repertorium, 109 (1998) 329-335.

[12] J. Tanaka, C. Da Silva, A. De Oliveira, C. Nakamura and B. Dias Filho, Antibacterial activity of indole alkaloids from Aspidosperma ramiflorum. Brazilian Journal of Medical and Biological Research, 39 (2006) 387-391.

[13] L. Boulos, Flora of Egypt, vol. 1. Cairo: Al Hadara Publishing, 417 (1999)

[14] J.-Y. Lin and C.-Y. Tang, Determination of total phenolic and flavonoid contents in selected fruits and vegetables, as well as their stimulatory effects 
on mouse splenocyte proliferation. Food chemistry, 101 (2007) 140-147.

[15] C.-C. Chang, M.-H. Yang, H.-M. Wen and J.-C. Chern, Estimation of total flavonoid content in propolis by two complementary colorimetric methods. Journal of food and drug analysis, 10 (2002)

[16] D.K. Singh, B. Srivastava and A. Sahu, Spectrophotometric determination of Rauwolfia alkaloids: estimation of reserpine in pharmaceuticals. Analytical sciences, 20 (2004) 571-573.

[17] M.L. Price, S. Van Scoyoc and L.G. Butler, A critical evaluation of the vanillin reaction as an assay for tannin in sorghum grain. Journal of Agricultural and Food Chemistry, 26 (1978) 1214-1218.

[18] C.M. Liyana-Pathirana and F. Shahidi, Antioxidant activity of commercial soft and hard wheat (Triticum aestivum L.) as affected by gastric $\mathrm{pH}$ conditions. Journal of agricultural and food chemistry, 53 (2005) 2433-2440.

[19] P.R. Murray, K.S. Rosenthal and M.A. Pfaller, Medical microbiology. (2015): Elsevier Health Sciences.

[20] L. Liu, J. Yang and Y. Shi, Phytochemicals and biological activities of Pulicaria species. Chemistry \& biodiversity, 7 (2010) 327-349.

[21] A. Panche, A. Diwan and S. Chandra, Flavonoids: an overview. Journal of nutritional science, 5 (2016)

[22] P. Jaisankar, R.L. Gajbhiye, S.K. Mahato and D. Nandi, Flavonoid natural products: chemistry and biological benefits on human health: a review. Asian J. of $A d v$. Basic Sci, 3 (2014) 164-178.

[23] G. Hussain, A. Rasul, H. Anwar, N. Aziz, A. Razzaq, W. Wei, M. Ali, J. Li and X. Li, Role of plant derived alkaloids and their mechanism in neurodegenerative disorders. International journal of biological sciences, 14 (2018) 341.

[24] M. Bouaziz, R.J. Grayer, M.S. Simmonds, M. Damak and S. Sayadi, Identification and antioxidant potential of flavonoids and low molecular weight phenols in olive cultivar Chemlali growing in Tunisia. Journal of agricultural and food chemistry, 53 (2005) 236-241.

[25] A. Moure, J.M. Cruz, D. Franco, J.M. Domínguez, J. Sineiro, H. Domínguez, M.a.J. Núñez and J.C. Parajó, Natural antioxidants from residual sources. Food chemistry, 72 (2001) 145-171.

[26] C.A. Rice-Evans, N.J. Miller and G. Paganga, Structureantioxidant activity relationships of flavonoids and phenolic acids. Free radical biology and medicine, 20 (1996) 933-956.

[27] M. Biswas, P.K. Haldar and A.K. Ghosh, Antioxidant and free-radical-scavenging effects of fruits of Dregea volubilis. Journal of natural science, biology, and medicine, 1 (2010) 29.

[28] A. Babaei and A.R. Taheri, Direct electrochemistry and electrocatalysis of myoglobin immobilized on a novel chitosan-nickel hydroxide nanoparticles- carbon nanotubes biocomposite modified glassy carbon electrode. Anal. Bioanal. Electrochem, 4 (2012) 342-356.

[29] N.Q.M. Al-Hajj, H.X. Wang, C. Ma, Z. Lou, M. Bashari and R. Thabit, Antimicrobial and antioxidant activities of the essential oils of some aromatic medicinal plants (Pulicaria inuloides-Asteraceae and Ocimum forskolei-Lamiaceae). Tropical Journal of Pharmaceutical Research, 13 (2014) 1287-1293.

[30] A. Alamgir, Therapeutic use of medicinal plants and their extracts: volume 1: pharmacognosy. Vol. 73. (2017): Springer.

\section{How to cite this manuscript:}

\section{O.A. El-Shahaby, M.M. El-Zayat, R. Rabei and}

H.S. Aldesuquy,Phytochemical constituents, antioxidant activity and antimicrobial potential of Pulicaria incisa (lam.) DC as a folk medicinal plant. Progress in Chemical and Biochemical Research, 2 (2019), 222-227.

DOI: 10.33945/SAMI/PCBR.2019.4.7

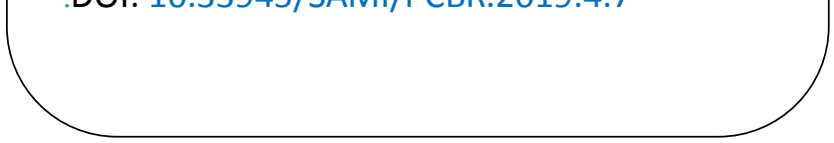

